\title{
Evaluation on the Warning-Degree of the Ecological Carrying Capacity of Guangzhou City Based on the DPSIR Model
}

\author{
MING-JIE LI ${ }^{1,2}$, JIE ZHANG ${ }^{1,3}$, YU-LIN ZHU ${ }^{2}$ \\ 1. Department of Economics and Finance, Huashang College Guangdong University of Finance \& \\ Economics, Guangzhou, Guangdong, CHINA \\ 2. School of economics, Central South University of Forestry and Technology, Changsha, Hunan, \\ CHINA \\ 3. Institute of Resources, Environment and Sustainable Development Research, Jinan University, \\ Guangzhou, Guangdong, CHINA
}

\begin{abstract}
Evaluation on the ecological carrying capacity is related to the sustainable development of cities. The evaluation requires a scientific, reasonable and intuitive evaluation method system. In order to evaluate the ecological carrying capacity of Guangzhou city, based on the "Driving-Pressure-State-Impact-Response (DPSIR)" model, this paper constructs a warning-degree evaluation index system for city, evaluates the ecological carrying capacity, judges the warning-degree of Guangzhou City from 2009 to 2018 by the method of entropy weight, and puts forward the countermeasures and suggestions to improve the city carrying capacity. The calculation result shows that the comprehensive index scores of the warning-degree evaluation of ecological carrying capacity of Guangzhou city are rising, the warning degree decrease from high to medium and low during the research period. Comparing each evaluation subsystem, there is a slight drop in the driving subsystem index scores, while pressure, impact and response index scores increase significantly. And the contribution proportion of each subsystem to the comprehensive index score is different. The pressure subsystem makes the biggest contribution. Therefore, Guangzhou should continue to encourage technological innovation, promote the use of clean production, implement energy conservation and emission reduction, and develop a green economy. The government should strengthen ecological and environmental protection legislation, and improve the economic policy system for ecological and environmental protection. The public should raise the environmental protection, ecological and participation awareness.
\end{abstract}

Key-Words: Ecological Carrying Capacity, Warning-degree, DPSIR Model, Guangzhou city

Received: May 11, 2020. Revised: September 3, 2020. Accepted: September 7, 2020. Published: September 16, 2020.

\section{Introduction}

In 2015, China put forward the overall strategic layout of "five-in-one" in economic, political, cultural, social and ecological civilization development, clarified the importance of ecological civilization development in the contemporary era. China once again stressed the need to "speed up the reform of the ecological civilization system and build a beautiful China" in 2017.

In recent years, Guangzhou city has made remarkable achievements in urbanization and industrialization. However, as a megacity, Guangzhou inevitably experienced a range of social and environmental problems such as excessive population growth, environmental pollution, ecological destruction, resource depletion and traffic congestion. The city's ecological carrying capacity is facing a huge challenge. In the future, Guangzhou needs to tackle the crucial issues of resource constraints and environmental pressure during its development.

Therefore, this study selects Guangzhou city as the subject to carry out the research on the warning-degree evaluation of ecological carrying capacity. Based on the DPSIR model and entropy weight theory, this paper constructs an ecological carrying capacity evaluation, regulation theoretical system of Guangzhou. Such a system integrates real-time monitoring, data collection, quantitative evaluation, dynamic prediction, hierarchical pre-warning, timely release and comprehensive regulation. Through the judgment and analysis of the warning degree, this paper can provide the basis for the formulation of ecological management policies in Guangzhou, and serves as a reference for other cities. 


\section{Literature Review \\ 2.1 Definition of the concept of ecological carrying capacity}

The research on "ecological carrying capacity" began in the 1920s. After the publication of the "Declaration of the United Nations Conference on the Human Environment" in 1972, more researches on this aspect were seen and fruitful results were achieved.

Carrying capacity was originally a concept in physical mechanics. Park and Burges (1921) first introduced this concept into the field of ecology from the perspective of population quantity. On this basis, Holing (1973) proposed a more standardized concept of "ecological carrying capacity". He indicated that "ecological carrying capacity is the ability of the ecosystem to resist external interference, maintain the original ecological structure and ecological function and maintain relative stability". With the continuous development of the economy and society, the problems of population, environment and resources were increasingly prominent. Researches on carrying capacity based on different needs and emphases were frequently seen. Concepts such as population carrying capacity [1-2], resource carrying capacity [3-4] and environmental carrying capacity [5] were emerged one after another.

With the theory of sustainable development put forward in the 1980s, researches on ecological carrying capacity were combined with sustainable development and ecological civilization construction, which provided a new perspective for the researches on ecological carrying capacity and encouraged scholars to make more comprehensive thinking on the connotation and elements of carrying capacity. Scholars discussed the coordination of resources, environmental carrying capacity and population and economic development from the perspective of "nature-economy-society-human". Although there is no unified definition of urban ecological carrying capacity at present, it is generally believed that the urban ecological carrying capacity should be the capacity of self-maintenance, self-regulation and self-development of the ecosystem in a specific period of time and within the specific area of the city, the number of population that the resources and environment subsystem can sustain, and the capacity to maintain the sustainable development of ecology, economy and society [6-8].

\subsection{Improvement of evaluation method of ecological carrying capacity}

With the gradual maturity of the theory of ecological carrying capacity, there are more and more evaluation methods, which are mainly quantitative research and static research. The evaluation methods and models used mainly include the NPP method of natural vegetation [9], emergy analysis model [10], and ecological footprint theory [11], etc.

Constructive researches have been conducted on ecological carrying capacity by using the logistic method for population quantity [12], state space method [13], resource supply and demand balance method [14], etc. However, in the aspect of warning-degree evaluation and regulation of ecological carrying capacity, although the concept system of the warning theory and the operation methods are relatively perfect, warning-degree evaluation and regulation are rarely applied in the research of ecological carrying capacity.

Chinese scholars mainly adopts mathematical models for quantitative evaluation to study urban ecological carrying capacity. Specifically, in addition to using the emergy analysis model[15-16], ecological footprint theory [17-20] and state space method [21], "Hu Line" theory [22-23], comprehensive index method [24], analytic hierarchy process [25], fuzzy comprehensive method [26-27] and grey weighted correlation degree method [28-30] have been applied to evaluate the urban ecological carrying capacity.

\subsection{Expansion of spatial scale of ecological carrying capacity evaluation research}

Judging from the relevant researches, the spatial scale of ecological carrying capacity evaluation research extends from small scale and small space to large scale and large space. Small-scale and small-space evaluation is mainly applicable to micro-ecosystems such as communities, landscapes, watersheds and cities (counties), which is helpful to deeply and carefully explore the impact mechanism of system ecological carrying capacity. while large-scale and large-space evaluation research is mainly used for national and regional ecological carrying capacity evaluation. Decision-makers can grasp the status of ecological carrying capacity from a macro perspective and formulate clear macro-management strategies. Overall, researches on the evaluation of ecological carrying capacity are mainly based on the natural ecosystem, and researches regarding urban scale are rarely seen.

\subsection{Development of evaluation index system of urban ecological carrying capacity}

Quantitative evaluation methods are generally carried out on the basis of constructing an evaluation index system. Researches on this aspect have shifted from a single-index, simple and partial 
process to a multi-index, complex, and comprehensive process. In the current researches, The index system constructed by scholars roughly includes the following three categories. Firstly, an index system is constructed from three aspects of nature, society and economy based on the theory of "nature-society-economy" artificial composite ecosystem[6,31]. Secondly, an index system from three aspects of pressure, state and response is constructed based on the theories put forward by the United Nations Environment Programme and other departments[30,32]. Thirdly, an index system from three aspects of driving, state and response is constructed based on the theory put forward by the Commission On Sustainable Development of the UN [33].

Making a comprehensive survey of the relevant researches on urban ecological carrying capacity, many achievements have been made, and the research methods and conclusions serve as references for this paper. However, there are still some deficiencies. (1) These achievements are mainly about the evaluation of the current situation of ecological carrying capacity, but rarely about prediction, warning-degree and regulation based on evolution trend. (2) The index system for warning-degree evaluation of urban ecological carrying capacity needs to be improved. (3) The methods of evaluation and warning-degree of ecological carrying capacity need to be standardized.

\section{Research Subject and Model 3.1 Research Subject}

Guangzhou, referred to as "Sui" for short, also known as the rams and flower city, is the capital of Guangdong province and the political, economic, scientific and technological, educational and cultural center of South China. It is a national central city, a megacity, and China's important central city, international business center and comprehensive transportation hub approved by the State Council. Located in southern China, Guangzhou borders the South China Sea and the northern edge of the Pearl River Delta. It is a national comprehensive gateway city and the first batch of coastal open cities. It is also China's southern gateway to the world, the central city of Guangdong-Hong Kong-Macao Greater Bay Area, the pan-Pearl River Delta Economic Zone and the hub city of the Belt and Road Initiative.

By the end of 2018, Guangzhou had an urban area of 7,434.4 sq.km., a GDP of RMB2,285.935 billion, a resident population of $14,904,400$, an urbanization rate of $86.38 \%$, and a per capita disposable income of RMB59,982. In recent years, Guangzhou has continued to deepen reform and opening-up, promoted high-quality development, further enhanced structural reforms on the supply side, accelerated industrial transformation and upgrading, vigorously developed the new economy and foster new momentum. In terms of environmental protection, Guangzhou insists on "improving environmental quality and safeguarding environmental safety" as the core to promote the continuous improvement of atmospheric, water and soil environmental quality. In 2018, the number of days with good ambient air quality was 294 , with $80.5 \%$ reaching the standard. The average annual concentration of $\mathrm{PM}_{2.5}$ was $35 \mathrm{ug} / \mathrm{m}^{3}$, making Guangzhou the leader in reaching the national secondary standard. The average concentration of sulfur dioxide was $10 \mathrm{ug} / \mathrm{m}^{3}$, down $16.7 \%$ year on year. The average concentration of nitrogen dioxide was $50 \mathrm{ug} / \mathrm{m}^{3}$, down $3.8 \%$ year on year. and the water quality compliance rate of centralized drinking water sources in cities had remained stable at $100 \%$.

\subsection{DPSIR model}

DPSIR model is developed from the PSR model proposed by the Organization for Economic Cooperation and Development (OECD) and United Nations Environment Programme (UNEP). It was first proposed by the European Environment Agency (EEA) in 1993 and has been widely used in ecological environment system evaluation. The model includes five aspects: Driving, Pressure, State, Impact and Response.

In this model, "Driving" is the internal cause of changes in ecosystem resources and environment, mainly referring to the internal driving force and development trend in social and economic activities. "Pressure" is the impact of human production, life and demand acquisition on the surrounding resources and environment, and is the direct cause of changes in resources and environment. "State" is the various conditions of regional resources and environment under the above-mentioned "Driving" and "Pressure", and is the outcome of the joint action of the above-mentioned two factors. "Impact" is the feedback outcome and impact degree of various states of the system on regional resources, environment, economy, society and human health. "Response" refers to the active regulatory measures taken by human beings to promote the sustainable development of regional social economy [34].

DPSIR model is an important model used to 
measure and evaluate urban ecological carrying capacity. It analyzes the interaction between human beings and ecosystems from the perspective of system theory and serves as an effective tool to judge the state of ecosystems and the causal relationship between ecological problems. It is also a common model that is comprehensive, integral, systematic and flexible, and can be used to comprehensively analyze and describe ecological problems and their relationship with economic and social development [35].
Based on the DPSIR model, this paper refers to the ecological civilization construction assessment target system of Guangdong Province and green development index system of Guangdong Province, follows the basic principles of index system construction-comprehensiveness, representativeness, hierarchy, scientificity, comparability and operability and constructs a warning-degree evaluation index system of ecological carrying capacity of Guangzhou city. Details are shown in Table 1:

Table 1. The Warning-degree evaluation index system of the ecological carrying capacity of Guangzhou City

\begin{tabular}{|c|c|c|}
\hline Criteria layer & Index layer & Index attribute \\
\hline \multirow{7}{*}{ Driving } & Resident population density (D1) & Negative \\
\hline & Natural growth rate of population (D2) & Negative \\
\hline & Urbanization rate of resident population (D3) & Negative \\
\hline & Engel's coefficient of urban households (D4) & Negative \\
\hline & Per capita GDP (D5) & Positive \\
\hline & GDP growth rate (D6) & Negative \\
\hline & Coefficient of foreign trade (D7) & Negative \\
\hline \multirow{9}{*}{ Pressure } & Energy consumption for every RMB10,000 of GDP (P1) & Negative \\
\hline & Electricity consumption for every RMB10,000 of GDP (P2) & Negative \\
\hline & Water consumption for every RMB10,000 of GDP (P3) & Negative \\
\hline & Per capita water consumption of residents (P4) & Negative \\
\hline & Discharge of industrial wastewater per unit area (P5) & Negative \\
\hline & Emission of industrial waste gas per unit area (P6) & Negative \\
\hline & Emission of sulfur dioxide per unit area (P7) & Negative \\
\hline & Emission of industrial smoke and dust per unit area (P8) & Negative \\
\hline & Generated amount of general industrial solid waste per unit area (P9) & Negative \\
\hline \multirow{9}{*}{ State } & Per capita water resources $(\mathrm{S} 1)$ & Positive \\
\hline & Per capita construction land area (S2) & Negative \\
\hline & Per capita urban road area (S3) & Positive \\
\hline & Annual precipitation (S4) & Positive \\
\hline & Per capita park green space area (S5) & Positive \\
\hline & Greening rate of built-up area (S6) & Positive \\
\hline & Forest coverage (S7) & Positive \\
\hline & Per capita disposable income of urban residents (S8) & Positive \\
\hline & Contribution rate of the tertiary industry to GDP growth (S9) & Positive \\
\hline \multirow{7}{*}{ Impact } & Annual daily average of sulfur dioxide in urban area (I1) & Negative \\
\hline & Annual daily average of nitrogen dioxide in urban area (I2) & Negative \\
\hline & Average concentration of inhalable particles in urban area (I3) & Negative \\
\hline & PH value of precipitation (I4) & Negative \\
\hline & Acid rain frequency (I5) & Negative \\
\hline & Days of good ambient air quality (I6) & Positive \\
\hline & Day mean equivalent sound level of road traffic noise (I7) & Negative \\
\hline \multirow{8}{*}{ Response } & Comprehensive utilization rate of industrial solid waste (R1) & Positive \\
\hline & Centralized treatment rate of sewage treatment plants (R2) & Positive \\
\hline & Harmless treatment rate of municipal solid waste (R3) & Positive \\
\hline & Gas penetration rate $(\mathrm{R} 4)$ & Positive \\
\hline & Number of buses for every 10,000 people (R5) & Positive \\
\hline & Number of college students among every 10,000 people (R6) & Positive \\
\hline & Proportion of science and technology expenditure in fiscal expenditure (R7) & Positive \\
\hline & Proportion of education expenditure in fiscal expenditure (R8) & Positive \\
\hline
\end{tabular}




\section{Analysis Process \\ 4.1 Data sources}

During the composition of this paper, the authors collect the all original data of the above indexes for the evaluation of the warning-degree of the ecological carrying capacity of Guangzhou city for the years of 2009 to 2018. The data mainly come from the China City Statistical Yearbook (2010-2019), the China Statistical Yearbook on the Environment (2010-2019), the Guangdong Statistical Yearbook (2010-2019), the Guangzhou Statistical Yearbook (2010-2019), the National Economic and Social Development Statistical Bulletin of Guangzhou (2010-2019), the Environmental Statistical Bulletin of Guangzhou (2010-2019), and the Water Resources Bulletin of Guangzhou (2010-2019), etc.

\subsection{Determination the standard values of the evaluation indices}

The determination the standard values of the evaluation indices is the premise and foundation of the warning-degree evaluation of ecological carrying capacity and the warning degree analysis. Referring to the relevant research results of experts and scholars, both domestic and from abroad [30-35], this paper mainly adopts the methods shown below when determining the standards for evaluation indices:

(1) International and domestic standard values: For indexes with specific standards that have been formulated or promulgated internationally, domestically, or in related industries, their standards are determined according to relevant standards. For example, the standard indexes, including resident population density, natural rate of population growth, energy consumption for every RMB 10,000 of GDP, electricity consumption for every RMB 10,000 of GDP, water consumption for every RMB 10,000 of GDP, emission of industrial waste gas per unit area, emission of industrial smoke and dust per unit area, and generated amount of general industrial solid waste per unit area are determined based on relevant international and domestic standards such as the "National Ecological Civilization Construction Pilot Demonstration Zone Indexes", "Ecological County, Ecological City, Ecological Province Construction Indicators (Revised)" and "Environmental Air Quality Standards".

(2) Relative values: The standard values are determined according to the economic development level of Guangzhou city, the development goals for regional ecological civilization construction, and the people's yearning for a better life. For example, the standard indexes such as per capita GDP, GDP growth rate, forest coverage, per capita disposable income of urban residents, proportion of science and technology expenditure, and proportion of education expenditure are determined according to this method.

(3) Reference values: Indexes without specific standards are determined by referring to the standards of the evaluation on the warning-degree of the ecological carrying capacity that have been determined by relevant research or by consulting experts and scholars in the fields of urban economics and environmental economics. For example, the standards of foreign trade coefficient, urban per capita water resources, urban per capita construction land area, urban per capita road area, number of buses for every 10,000 individuals, number of college students among every 10,000 individuals, and other indexes are mainly determined by this method.

\subsection{Normalization of original data}

After the original data are collected, we find that the dimensions of the indicators are different. And the attribute of the indicators are also different, there are both positive and negative indicators. Such original data are not comparable. If the original data directly used for calculation and evaluation analysis, there would be a big discrepancy in the evaluation results. The original data cannot be directly calculated, summarized, evaluated and analyzed. Therefore the original data should be normalized firstly to make the index data more reasonable, so as to ensure the smooth progress of the warning-degree evaluation and make the evaluation results more intuitive and accurate.

The normalization processing of the original data includes the dimensionless processing of original data and the positive processing of negative indexes, which can eliminate the differences between the dimensions and index attribute of the original data. In this paper, the normalization process of the original data is as follows:

$$
\begin{aligned}
& \text { Positive indexes, } x_{i j}^{\prime}=\left\{\begin{array}{c}
100, x_{i j} \geq M_{j} \\
\frac{x_{i j}}{M_{j}} \times 100, x_{i j}<M_{j}
\end{array}\right. \\
& \text { Negative indexes, } x_{i j}^{\prime}=\left\{\begin{array}{c}
100, x_{i j} \leq M_{j} \\
\frac{M_{j}}{x_{i j}} \times 100, x_{i j}>M_{j}
\end{array}\right.
\end{aligned}
$$

$x_{i j}(\mathrm{i}=1,2,3, \ldots, 10 . \mathrm{j}=1,2,3, \ldots, 40)$ is the original data of the $\mathrm{j}^{\text {th }}$ evaluation index in the $\mathrm{i}^{\text {th }}$ year. $x_{i j}{ }^{\prime}$ is the value of the $\mathrm{j}_{-}^{\text {th }}{ }^{\text {index }}$ in the $\mathrm{i}^{\text {th }}{ }^{\text {th }}$ year after 
normalization processing. $M_{j}$ is the standard value of the $\mathrm{j}^{\text {th }}{ }^{\text {t }}$ evaluation index determined in the above text. Through the above processing, the values of all indexes could be turned into values within the range of $[0,100]$.

\subsection{Calculation of the comprehensive evaluation index of the warning-degree of the ecological carrying capacity of Guangzhou city}

Numerous methods have been proposed to calculate the comprehensive evaluation index of the warning-degree of the ecological carrying capacity, including the analytic hierarchy process, fuzzy comprehensive evaluation method, factor analysis method, and grey weighted correlation degree method, etc. In this paper, the entropy weight method is used to calculate the comprehensive evaluation index for the warning-degree of the ecological carrying capacity of Guangzhou city.

In information theory, information is a measure of the degree of order in a system, while entropy is a measure of the degree of disorder in the system. The absolute values of the two are equal and the directions are opposite. The smaller the information entropy of a certain index, the greater the amount of information provided by the index, the greater the role it plays in the comprehensive evaluation and the higher the weight it has. The entropy weight method is an objective weighting method. The entropy weight method uses the information entropy to calculate the entropy weight of each index according to the variation degree of each index and corrects the weight of each index through the entropy weight, thus obtains a more objective index weight. The process of calculating the comprehensive evaluation index of the warning-degree of the ecological carrying capacity of Guangzhou city by the entropy weight method is as follows:

(1) Calculate specific proportion $p_{i j}$ of the $\mathrm{j}^{\text {th }}{ }^{\text {th }}$ index value in the $\mathrm{i}^{\text {th }}$ year. $p_{i j}$ is calculated as following:

$$
p_{i j}=x_{i j}^{\prime} / \sum_{i=1}^{10} x_{i j}^{\prime}
$$

(2) Calculate the value of information entropy $E_{j} . E_{j}$ is calculated as following:

$$
E_{j}=(-1 / \ln 10) \times \sum_{i=1}^{10} p_{i j} \ln p_{i j}
$$

(3) Calculate the value of information entropy redundancy $D_{\mathrm{j}} . D_{j}$ is calculated as following: $D_{j}=1-E_{j}$
(4) Calculate the value of weight $W_{j}$ of each index. $W_{j}$ is calculated as following:

$$
W_{j}=D_{j} /\left(40-\sum_{j=1}^{40} E_{j}\right)
$$

The weights of each index calculated by the above formula are shown in Table 2:

Table 2. The weights of each evaluation index of the

\begin{tabular}{|c|c|c|c|}
\hline & & \\
\hline Indexes & Weight & Indexes & Weight \\
\hline D1 & 0.0093 & S5 & 0.0097 \\
\hline D2 & 0.0691 & S6 & 0.0205 \\
\hline D3 & 0.0601 & S7 & 0.0010 \\
\hline D4 & 0.0302 & S8 & 0.0412 \\
\hline D5 & 0.0860 & S9 & 0.0555 \\
\hline D6 & 0.0588 & I1 & 0.0303 \\
\hline D7 & 0.0150 & I2 & 0.0029 \\
\hline $\mathrm{P} 1$ & 0.0201 & I3 & 0.0066 \\
\hline $\mathrm{P} 2$ & 0.0122 & I4 & 0.0037 \\
\hline P3 & 0.0730 & I5 & 0.0560 \\
\hline P4 & 0.0363 & I6 & 0.0065 \\
\hline P5 & 0.0189 & I7 & 0.0001 \\
\hline P6 & 0.0046 & R1 & 0.0003 \\
\hline P7 & 0.0542 & $\mathrm{R} 2$ & 0.0088 \\
\hline P8 & 0.0362 & $\mathrm{R} 3$ & 0.0005 \\
\hline P9 & 0.0127 & $\mathrm{R} 4$ & 0.0001 \\
\hline S1 & 0.0233 & $\mathrm{R} 5$ & 0.0073 \\
\hline S2 & 0.0146 & R6 & 0.0050 \\
\hline S3 & 0.0049 & R7 & 0.0834 \\
\hline S4 & 0.0083 & $\mathrm{R} 8$ & 0.0128 \\
\hline
\end{tabular}
warning-degree of the ecological carrying capacity of

Guangzhou City

(5) Calculate score of the $\mathrm{j}^{\text {th }}{ }^{\text {th }}$ index in the $\mathrm{i}^{\text {th }}$ year. score $_{i j}$ is calculated as following: score $_{i j}=x_{i j}{ }^{\prime} \times W_{j}$

(6) Calculate comprehensive evaluation index score for the warning-degree of the ecological carrying capacity of Guangzhou city in each year. $S C O R E_{i}$ is calculated as following:

$\operatorname{SCORE}_{i}=\sum_{j=1}^{40}$ score $_{i j}$

According to the above calculation process, the comprehensive evaluation index scores of the warning-degree method of ecological carrying capacity of Guangzhou city and the index scores of the five subsystems from 2009 to 2018 are as shown in Fig 1 and Fig 2: 


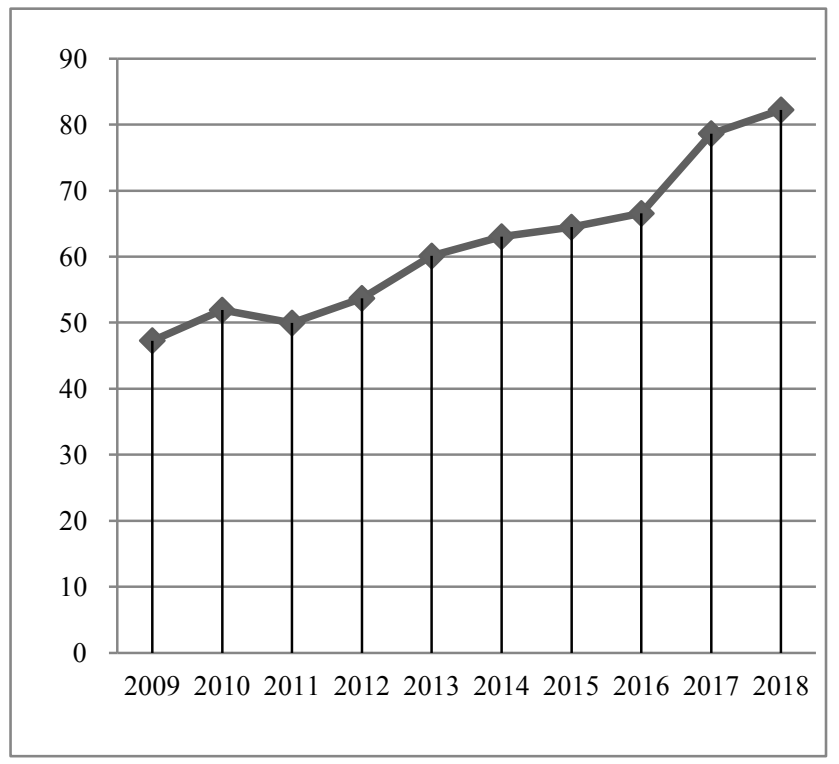

Fig 1. The comprehensive evaluation index scores of the warning-degree of the ecological carrying capacity of Guangzhou City

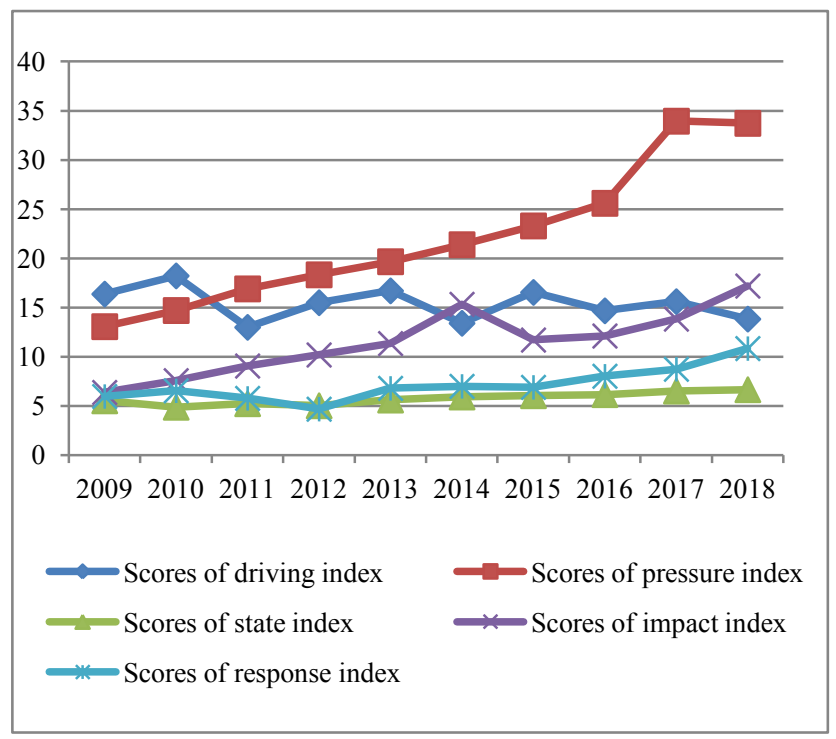

Fig 2. The index scores of five subsystems of the warning-degree of the ecological carrying capacity of Guangzhou City

\subsection{Determination of the warning degree of the ecological carrying capacity of Guangzhou city}

According to the degree of impact of human activities on resources and environment, the coordination relationship between human beings and ecosystems, and the degree of damage to urban ecosystems, and by referring to the existing outcomes of relevant experts and scholars, both domestic and from abroad [30-35], this study takes the criteria shown in Table 3 as the basis for judge the warning degree of the ecological carrying capacity of Guangzhou city.
Table 3. The criteria for the warning degree of the ecological carrying capacity of Guangzhou City

\begin{tabular}{cc}
\hline Score interval & Warning degree \\
\hline$[85,100]$ & No \\
{$[70,85)$} & Low \\
{$[50,70)$} & Medium \\
{$[30,50)$} & High \\
{$[15,30)$} & Severe \\
{$[0,15)$} & Significant \\
\hline
\end{tabular}

The description of the no warning degree: The function of the urban ecosystem remains intact and undamaged. The system is in a relatively safe state. The relationships among humans, nature, and ecology are coordinated, and the impact of human activities on resources and the environment is small. The description of low warning degree: The function of the urban ecosystem has been slightly damaged but can be controlled in time. The relationships among humans, nature, and ecology are relatively coordinated, and the impact of human activities on resources and the environment is relatively small.

The description of the medium warning degree: The urban ecosystem is considerably damaged and the function of the system of urban ecosystem is affected to some extent, but the basic operation can still be maintained. The relationships among humans, nature, and ecology are facing certain threats. Human activities have certain impacts on resources and the environment.

The description of the high warning degree: The urban ecosystem is greatly damaged and the function of the system is greatly affected, reconstruction or restoration is facing certain difficulties, the relationships among humans, nature, and the ecosystem are facing great threats, and human activities bring great impacts on resources and the environment.

The description of the severe warning degree: The urban ecosystem is severely damaged and the function of the system is greatly threatened, reconstruction or restoration is facing great difficulties, the relationships among humans, nature, and the ecosystem are out of balance to a certain extent, and human activities bring obvious impacts on resources and the environment.

The description of the significant warning degree: The urban ecosystem is extensively damaged. the function of the system is lost, and it is difficult to recover. The relationships among humans, nature, and the ecosystem are out of balance, and human activities bring serious threats to resources and the environment. 


\section{Conclusions and Suggestions}

Based on the DPSIR model, this paper constructs an evaluation index system for the warning-degree of ecological carrying capacity of Guangzhou city, uses the entropy weight method to carry out the evaluation, and judges the warning degree of ecological carrying capacity for each year of the study period. The results show that:

(1) The comprehensive index scores of the warning-degree of ecological carrying capacity of Guangzhou city show a rising trend in the past decade. The warning degrees show a changing trend of severe degree-medium degree-low degree. The ecological carrying capacity of the city is found to have improved, thus showing sound development momentum.

(2) Comparing each evaluation subsystem, there is a slight drop in the driving subsystem index scores, while pressure, impact and response index scores increase significantly. This shows that in recent years, Guangzhou city has achieved obvious results in strengthening its ecological environment protection and comprehensive management, improving energy conservation and emission reductions, and enhancing natural ecological protection.

(3) The contributions of the five subsystems for the comprehensive index scores are different. The contribution of the pressure subsystem far exceeds those of the other four. In 2018, the contributions of the driving, pressure, state, impact, and response subsystem respectively are $16.82 \%, 41.02 \%, 8.09 \%$, $20.91 \%$ and $13.17 \%$. Comparatively speaking, the driving, state, impact and response subsystem also have broad room for improvement.. Therefore, in the future, when improving the ecological carrying capacity of Guangzhou city, attention should be paid to the coordinated development of the five subsystems.

Based on the evaluation of the ecological carrying capacity of Guangzhou city and the analysis of the warning degree, this paper provides a certain reference for Guangzhou city to improve its ecological carrying capacity in the future and a basis for formulating relevant ecological environment policies. The following countermeasures are put forward to improve the ecological carrying capacity of Guangzhou city:

(1) The pressure subsystem contributes the most to the comprehensive evaluation index score of the warning-degree. Therefore, it is necessary to continue to encourage technological innovation, promote the use of cleaner production, vigorously implement energy conservation and emission reductions, and develop a green economy. In addition, efforts should be made to further reduce the energy consumption for every RMB 10,000 of GDP, reduce the electricity consumption for every RMB 10,000 of GDP, reduce the water consumption for every RMB 10,000 of GDP, and reduce the per capita water consumption of residents, the discharge of industrial wastewater per unit area, the emission of industrial waste gas, the emission of sulfur dioxide, the emission of industrial smoke and dust, as well as the generated amount of general industrial solid waste per unit area.

(2) It is necessary to introduce policies on ecological environment protection, re-enact the Environmental Protection Regulations of Guangzhou City, and implement a strict environmental protection system. Moreover, efforts should be made to improve the economic policy system for ecological environment protection, strengthen financial security, focus on the comprehensive treatment of environmental pollution in water, gas, soil, and major environmental infrastructure construction and other projects, and increase the proportion of science and technology expenditure and the proportion of education expenditure.

(3) Guangzhou city should constantly enhance the public's awareness of environmental protection, ecology, and participation, establish the concept of moderate consumption and resource conservation, and form a healthy, civilized, and scientific lifestyle. Moreover, it should vigorously create a conservation-oriented government, green families, green schools, and green communities, carry out green travel and garbage sorting, consciously practice a low-carbon lifestyle, and reduce the emission of domestic pollutants.

\section{References:}

[1]R. Dewar. Environmental Productivity (1984). Population Regulation and Carrying Capacity. American Anthropologist, 86(3), 601-614.

[2]J. Cohen (1995). Population Growth and Earth's Human Carrying Capacity. Science, (269), 341-346.

[3]W. Aiken (1980). The Carrying Capacity Equivocation. Social Theory and Practice, 6(1), 1-11.

[4]D. Price (1999). Carrying Capacity Reconsidered. Population and Environment, 21(1),5-26.

[5]M. Hoeprich. and R. Widner (1980). Environmental Factors and Bearing Damage. SAE Transactions, 89(2), 2247-2257.

[6]Gao Jixi (2001). Discussion on the theory of Sustainable Development-Theory, Method and 
Application of ecological carrying Capacity. China Environmental Science Press, Beijing, China.

[7]J. Karr, T. Thomas (1996). Economics, Ecology, and Environmental Quality. Ecological Applications, 6(01), 31-32.

[8]Angela M. Guerrero, Nathan J. Bennett, Kerrie A. Wilso (2018). Achieving the promise of integration in social-ecological research: a review and prospectus, 23(3), 37-63.

[9]J. Davis (1953). Natural Vegetation, Florida's Basic Resource. Quarterly Journal of the Florida Academy of Sciences, 16(2),75-77.

[10]M. Slesser, H. Odum, and D. Huettner (1977). Energy Analysis. Science, 196 (4287),259+261-262. [11]M. Wackernagel, L. Lewan, and C. Hansson (1999). Evaluating the Use of Natural Capital with the Ecological Footprint: Applications in Sweden and Subregions. Ambio, 28 (7),604-612.

[12]N. Meade(1988). A Modified Logistic Model Applied to Human Populations. Journal of the Royal Statistical Society. Series A (Statistics in Society), 151 (3), 491-498.

[13] Marinél Willemse, Bronwyn J. Goble (2018). A Geospatial Approach to Managing Coastal Access in KwaZulu-Natal, South Africa. Journal of Coastal Research, 34 (2), 282-292.

[14]M. Fasiolo, N. Pya and S. Wood (2016). A Comparison of Inferential Methods for Highly Nonlinear State Space Models in Ecology and Epidemiology. Statistical Science, 31 (1), 96-118.

[15]Tang Quanhua (2015). Evaluation of sustainable development of complex ecological economic system in Taiyuan city based on energy theory. Shanxi Normal University, Taiyuan, China.

[16]Chu Fangfang and Jiang Difei (2012). Evolutionary tendency of ecological-economic system in chang-zhu-tan city cluster based on emergy analysis. Economic geography, 32(02), 143-148.

[17]Song Xuejun, Wang Duoduo, Qian Fei and Cai Yongli (2018). Ecological footprint and ecological carrying capacity analysis of yangtze river delta urban agglomeration in 2010. Ecological science, 37(02),162-172.

[18]Zhao Dongsheng, Guo Caiyun, Zheng Du, Liu Lei and Wu Shaohong (2019). Research progress of ecological carrying capacity. Acta Ecologica Sinica, 39(02),399-410.

[19]Ma Weijing, Liu Bin, Yang Dewei, Xu Lingxing and Guo Qingmei (2018). Spatial and temporal evolution of watershed ecological carrying capacity based on ecological footprint model. Environmental Science \& Technology, 41(01),163-171.

[20]Ren Caifeng, Cheng Yanshu, Zheng Xin and
Zhou Lizhi (2019). Research on natural capital utilization in huaibei city based on ecological footprint model. Ecological Science, 38(06), 106-114.

[21]Mao Peng, Lin Aiwen, Yang Qian and Zhu Hongjie (2017). Evaluation of regional ecological carrying capacity of urban agglomeration in middle Reaches of Yangtze River based on state space method. Geomatics \& Spatial Information Technology, 40(03),37-41.

[22]Zhong Maochu (2016). How to represent regional ecological carrying capacity and ecological environment quality? Meanwhile, the ecological carrying capacity of $\mathrm{Hu}$ line is reclassified into the eastern and western regions. Journal of China University of Geosciences(Social Sciences Edition), 16(01),1-9.

[23]Zhong Maochu and Sun Kunxin (2018). Relative characterization of urban ecological carrying capacity in China: analysis from the $\mathrm{Hu}$ Line. Areal Research and Development, 37(05),152-157.

[24]Shen Yanping, Guo Changhong and Wang Qian (2008). A study on the assessment system of urban eco-security and pattern analysis of Henan Province. Journal of Safety and Environment, (03),89-93.

[25]Ma Xinping, Long Shuangshuang, Li Yuting and $\mathrm{Wu}$ Tao (2020). Research on warning-degree and evaluation of ecological security in Guanzhong city agglomeration of Shaanxi province based on DPSR model. Scientific and Technological Management of Land and Resources, 37(01),82-94. [26]Qin Cu, Dai Wen and Yang Qin (2014). Study on urban ecosystem security based on entropy weight fuzzy comprehensive evaluation method. Journal of Northwest Normal University(Natural Science), 50(02),110-114.

[27] Gu Chenglin and Li Xueming (2012). Comprehensive evaluation of urban ecological environment quality of Dalian city based on fuzzy comprehensive evaluation method. Environmental Science and Management, 37(03), 172-179+187.

[28]Wu Xiao and Wu Yijin (2014). Study of Wushan County in Chongqing for dynamic evaluation of ecological security in mountain cities based on grey relational model. Resources and Environment in the Yangtze Basin, 23(03),385-391.

[29]Chi Guotai and Zhang Nan (2011). An ecosystem evaluation model based on AHM-correlation analysis and an empirical research on 14 cities of Liaoning province. Management Review, 23(07), 25-33.

[30]Zhu Yulin, Li Mingjie and Gu Ronghua (2017). Security prewarning research on ecological carrying 
capacity of Changzhutan urban agglomeration based on pressure-State-response model. Resources and Environment in the Yangtze Basin, 26(12),2057-2064.

[31]Chris Malcolm (2020). Ecocomplicity and the Logic of Settler-Colonial Environmentalism. Resilience: A Journal of the Environmental Humanities, 7(2-3), 106-131.

[32] A. Berger, R. Hodge (1998). Natural Change in the Environment: A Challenge to the Pressure-State-Response Concept. Social Indicators Research, 44(02),255-265.

[33]Zhang Huiheng and Wei Yanjie (2016). A measurement of development level of Anhui's ecological civilization based on DSR model. Journal of Fuyang Normal University(Social Science Edition), (04),5-10.

[34]C. Binder, J. Hinkel, P. Bots, and C. Wostl (2013). Comparison of Frameworks for Analyzing Social-ecological Systems. Ecology and Society, 18(04),85-94.

[35]S. Odermatt (2004). Evaluation of Mountain Case Studies by Means of Sustainability Variables: A DPSIR Model as an Evaluation Tool in the Context of the North-South Discussion. Mountain Research and Development, 24(04),336-341.

\section{Contribution of individual authors}

Ming-Jie Li has organized and executed the research model, and presented the research conclusion.

Jie Zhang carried out the literature review, established the standard values of evaluation indexes.

Yu-Lin Zhu was responsible for the data collection and statistics.

\section{Acknowledgement}

This research was supported by the following fund which we thank for. And the authors would take all responsibility for this paper.

2019 annual project of the 13th Five-Year Plan for the Development of Philosophy and Social Science of Guangzhou (Project Number: 2019GZGJ210).

\section{Creative Commons Attribution License 4.0 (Attribution 4.0 International, CC BY 4.0)}

This article is published under the terms of the Creative Commons Attribution License 4.0

https://creativecommons.org/licenses/by/4.0/deed.en_US 